\title{
Orta Asya Türk Topluluklarında Kadim Bir Bozkır Geleneği: Baranta
}

\author{
An Ancient Tradition of The Steppe in Central Asian Turkish \\ Communities: Baranta
}

\begin{abstract}
Coşkun KUMRU*
Öz: Baranta genel mânâda Orta Asya Türk topluluklarında bir hukuksuzluğa karşı örf ve adetler dâhilinde yağma maksatlı yapılan akın olarak tanımlanabilir. Bu âdet modern zamanlara kadar Kazak ve Kırgız Türklerinin kültürlerinde devam etmiş, daha sonra değişen hukukî normlarla beraber etkisini yitirmiştir. Batılı birçok araştırmacının yanlış olarak çapul ve hırsızlık şeklinde tanımladığı baranta, Türklerin aynı zamanda günlük yaşam pratiğini de yansıtan bir gelenektir. Esasen bozulan adaleti tekrar tesis etmenin ve gayrimeşruluğu gidermenin bir yolu olarak görülmektedir. Barantanın şartlarının oluşabilmesi için belirli sebeplerin olması gerekirdi. Bunların arasında en önemlileri; törenin dışında fiillerde bulunmak, hırsızlık, tahkir ve adam öldürme gibi eylemlerdi. Söz konusu hukuksuzluklara ilişkin yargı yoluyla da bir çözüme varılamazsa kanunen haklı tarafın hakkını baranta yoluyla elde etmesine müsaade edilirdi. Baranta hadisesi bugüne kadar Türk araştırıcıları yeterince meşgul etmeyen bir konu olarak kalmıştır. Buna karşılık başta Rus araştırmacılar olmak üzere pek çok Batılı yazar söz konusu hadiseye sathî ve menfî yorumlarla dâhil olmuştur. Halbuki baranta hadisesi çağının bağlamından uzak değerlendirilmemesi gereken, meşru hukuk normları dâhilinde ele alınması gereken bir gelenektir. Çalışmamızda kaynaklarda ortaya çıkan malumat ve araştırıcıların baranta geleneğine ilişkin görüş ve tartışmaları üzerine genel bir bakış sunmaya çalıştık. Bununla birlikte kaynaklarda verilen bilgileri değerlendirirken tarihçilik mesleğinin en temel şartı olan tenkit ilkesini göz önünde bulundurarak malumatı eleştirel okumadan istisna tutmadik.
\end{abstract}

\section{Anahtar sözcükler: Baranta, Hukuk, Türkler, Orta Asya}

Abstract: The general meaning of baranta can be defined as plunder within customs against lawlessness in Central Asian Turkish Communities. This tradition continued in the Kazak and Kirghiz Turks's culture until modern times and then lost its effect through the change in legal norms. Baranta, which has been falsely described as raid and theft by many western scholars, is in fact a tradition which reflects the daily practise of the Turks. It was actually seen as a way of restoring corrupted justice and of eliminating illegitimacy. There should have been certain reasons for the conditions of the baranta to be applied. The most important of these were inappropriate actions in custom, robbery, insult and murder. In situations where a solution could not be reached through law, then it was allowed by law to obtain the right of the legitimate side through baranta. The baranta tradition has remained a subject that Turkish researchers have not engaged with to a sufficient extent, while, on the other hand, many Western writers, especially Russian researchers, have worked on this topic with superficial and negative comments. However, the baranta is a tradition that must be considered within the framework of that age and of its legitimate legal norms. We have attempted to present a full view of researchers' opinions and debates concerning the baranta tradition, but, while evaluating the information provided by the sources, we also consider the principle of criticism the most basic condition of the profession of historiography.

Keywords: Baranta, Law, Turks, Central Asia

\footnotetext{
* Arş. Gör., Pamukkale Üniversitesi, Fen-Edebiyat Fakültesi, Tarih Bölümü, Denizli. ckumru@pau.edu.tr, https://orcid.org/0000-0001-5852-6855
} 


\section{Giriş}

Özellikle XIX. yüzyıl boyunca birçok araştırmacı bozkır topluluklarındaki sosyal yapı üzerine incelemeler yapmıştır. Bu âlimler arasında bilhassa 1870'lerde Baykal Gölü Buryatları arasında çalışmalar yapan Afanasy Shchapov, Altayların güneyindeki Kırgız ve Kazaklar arasında incelemelerde bulunan Wilhelm Radloff ve A. V. Pozdneev alana önemli katkılarda bulunmuşlardır (Krader 1955, 75). Özellikle Wilhelm Radloff, Türk bozkır toplumunun sosyal nizamını detaylı olarak incelemiştir. Türklere ait gelenek, adet, yaşam ve düşünüş tarzı gibi pek çok hususu ayrıntılı olarak betimleyen Radloff, Kazak toplumunun ikametgâhlarını her daim sürülerine gıda temin edebilecekleri yerde kurduklarını belirtmektedir. Bununla birlikte Türk topluluğunun günlük yaşam pratiği hayvan sürülerine ve besin tedarikine sıkı sıkıya bağlıdır. Bozkırlarda hayvan besleyen bir kimse için kışlık ve yazlık olarak uygun bir yer bulmak meselesi bilhassa çok önemlidir. Çünkü muayyen bir mevsim için çoğu yer uygun gelmemektedir. Bozkır Türk topluluklarının yaşamlarının en temel koşulu ve varlık vasıtaları hayvanlarıdır. Hayvan kayıpları, diğer bir ifadeyle mal kayıpları Türklerde son derece ciddi bir sorun teşkil etmiştir. Hayvanlara (bilhassa koyun, keçi, sığır, at ve deve) Türklerce ne kadar önem verildiği selamlaşma esnasında söylenen "mal canıng amanna? (malın canın săg mı?)" cümlesinin kullanımından da anlaşılabilir (Radloff 1956, 426-431).

Görüldüğü üzere Türklerde sosyal nizam ve organizasyon şekilleri büyük ölçüde bozkır yaşamının gereklerine uygun şekilde teşekkül etmiştir. Bununla birlikte toplumsal düzenin sağlanmasında temel koşul olan örf (hukuk) Türklerce her daim önemli olmuştur. Zira Türklerce düzenin ve devletin devamı her şeyin üstünde görülürdü. Asya'da hukukun temeli olan geleneksel yasa Zang, däp, nark ve âdet gibi farklı isimlerle anılmaktadır. Bilindiği üzere âdet, geleneksel yasanın Arapçasıdır. Türkmenler buna däp derler. Bozkır konargöçerleri zang terimini kullanır. Kırgızlar ise karşılık olarak Nark sözcüğünü telaffuz eder. Tesis ettikleri hukukî düzenle sosyal hayatı belirli bir nizam altında toplamayı başaran Türkler, kültürünün gerektirdiği vasıflar ve her an düşmana karşı hazır bulunma zorunluluğundan dolayı disiplinli ve teşkilatlı olmak zorundalardı. Bu nedenle bozkır topluluklarında her boy belirli bir sosyal, iktisadî ve idarî teşkilata sahip olmuştur.

Eski Türklerde boyların temelini oluşturan yapı, oğuş veya ocak olarak da ifade edilen ailedir. Türk bozkır cemiyetinin temel yapısını oluşturan aile, kan akrabalığı esasına dayanan sosyal bünyenin çekirdeği durumundadır (Türk topluluklarında sosyal yapı için bk. Kafesoğlu 2017, 219-238). Birkaç ailenin çadırlarını kurarak yaşadıkları yere ise avul, avul topluluğunun meydana getirdiği kütleye oba veya oymak, onun üstündeki topluluğa da boy denilmekteydi. Başlarında bir başbuğ bulunan toplulukların mensupları, sürü ve otlaklarını elde tutabilmek için her türlü tehlikeye karşı hazır bulunurlar ve askeri bir nizamda yaşarlardı. Avula yapılan baskınlar (baranta) her zaman bir düşman tarafindan yapılmazdı, bazen de aynı topluluğun içinde birbirleriyle mücadele eden boylar tarafından da yapılabilirdi (Diyarbekirli 1972, 46-47). Örneğin birçok Türk boyunda olduğu gibi Peçeneklerin hayatı da bu esaslara göre tanzim edilmişti. Özellikle Uzların hücumları ve Uzlar tarafından baranta tehlikesi, Peçenekleri bunlara ilişkin tedbir almaya sevk eden nedenler arasındaydı (Kurat 1972, 58).

Türk bozkır geleneği kapsamında baranta hadisesinin tafsilatını analiz ederken söz konusu hususların göz ardı edilmemesi gerekmektedir. Zira bozkır Türk toplumundaki hukukî norm ve anlayışlar iktisadî ve sosyal nizâma sıkı sıkıya bağlıdır. Bu bakımdan baranta uygulamasını Türk bozkır yaşantısının bir parçası ve örf anlayışının tamamlayıcı bir unsuru olarak görmek yerinde olacaktır. 


\section{Baranta Kelimesi Üzerine}

Bozkır Türk toplumlarında geniş ölçüde kullanılan bir terim olan baranta, Türk lehçelerinde farklı şekillerde ifade edilmektedir. Kelime Kazakça'da Barymta şeklinde söylenmekte olup, düşman gruplar arasında haksızlığa karşı uygulanan ve suç sayılmayan at çalma pratiği olarak ifade edilmiştir (Kassymova et al. 2012, 46). Kelime, Kırgızca'da Barımta biçiminde söylenmektedir. Sözcügün mânâsını en doğru tanımlayan uzmanların başında ise K. K. Yudahin gelmektedir. Yudahin $(1998,89)$ Kırgız sözlüğünde barantayı, "Haksızlık edenin veya onun hisım, akrabalarının hayvanlarını sürüp götürmek maksadıyla yapılan hücumdur ki iddia edilen hakkı elde etme şekillerinden biriydi" ifadesiyle izah etmiştir.

Şeyh Süleyman Efendi, kelimenin Çağatayca karşılığını yağma, taraç, garet ve talan anlamını ihtiva eder biçimde Barant olarak vermiştir (Şeyh Süleyman Efendi-i Buharî 1881, 67). Aynı kelime Moğolca'da Barımta şeklinde söylenmektedir (Lessing 1960, 88). Gustaf John Ramstedt $(1952,7)$ baranta kelimesine misilleme, tutuklama, saldırı ve baskın anlamlarını yüklemektedir. Benzer şekilde Arminius Vambery $(1885,234)$ ve Martti Räsänen $(1969,63)$ de kelimeyi Raubzug yani çapul ve yağma anlamıyla ifade etmektedir.

Ziya Gökalp barantayı Kırgız ve Kazaklar'da akına verilen ad olarak tanımlamaktadır. Gökalp $(1991,294)$ bu akınlar sayesinde Türk ve Türkmen illerinin yoksulluk çekmediğini belirtmekte ve "Türkmen göçüdür vara vara düzelir" atasözünün ise söz konusu durumu ifade ettiğinin altını çizmektedir. Abdülkadir İnan $(1998,287)$ ise Avrupalı araştırmacıların söz konusu husustaki menfî değerlendirmelerini eleştirerek baranta hadisesinin kural ve kaideler bütünüyle uygulanan bir gelenek olduğunu vurgulamıştır.

Baranta terimi Rusça'ya da benzer anlamda geçmiştir. Alman dilbilimci Max Vasmer (1953, 54) Rus dilinin etimolojik sözlüğünde baranta kelimesinin Doğu Rusya ve Kafkaslarda kullanılmasının, bu sözcügün Türkçeden alındığına işaret ettiğini belirtmektedir. Kelimenin anlamları arasında ise misilleme, intikam, köylerin yıkımı, soygun ve çapulu zikretmektedir. Türkmenlerde baranta kelimesine karşılık Alaman tabiri de kullanılmaktadır. Radloff $(1893,367)$ bu terimi Räuberbande (soyguncu çetesi) olarak açıklamaktadır.

Batılı birçok araştırmacı baranta sözcüğünü izah ederken adeta devlet otoritesinin ve hukukî normların geçerliliğini yitirdiği, yağma, çapul ve düzensizliğin egemen olduğu bir toplumsal manzarayı betimlemektedir. Türk bozkır hayatına ilişkin yapılan değerlendirmelerde Türk cemiyetinin sosyal muhtevasını göz ardı eden yazarlar bu sebepten eksik ve hatalı neticelere varmışlardır.

\section{Barantanın Şartları, Uygulanışı ve Sonuçları}

Bozkır yaşantısı, tedarik edilen besinlerin ve konargöçer toplulukların sürüleri için gerekli olan su kaynaklarının güvenliği etrafında şekillenmiştir. Neredeyse Türklerin tükettiği tüm besinler ve savunma amaçlı kullanılan materyaller hayvanlardan elde edilmekteydi. Bir başka deyişle bozkırlarda bir kimsenin sürüsünün güvenliği hayatî bir önem taşımaktaydı. Bu nedenle Türkler, bozkır hayatının gerektirdiği çetin gereksinimlere uyum sağlayarak katı bir idarî ve sosyal nizam tesis etmişlerdir. Söz konusu husus göz önünde bulundurulduğunda baranta geleneğinin ifade ettiği anlam daha iyi anlaşılabilir.

Baranta bozkır Türk toplumlarında geçerli ve meşru bir müessese olup esasen bir hak arayış1 mücadelesini yansıtmaktadır. Bu durum XIX. yüzyılda Rus devletinin bünyesinde görev alan N. A. Mayev'in gözlemlerinde de kısmen ifade edilmiştir. Mayev'e göre, Baranta basit bir hırsızlık olarak görülemezdi. Bu nedenle de suç teşkil etmezdi. Konargöçerlerin tekdüze yaşamına bir çeşitlilik katan, birbirleriyle yakın ilişki kurdukları bir macera serisi ve bütünüyle bir manzume idi (Prior 2013, 56). Görülüyor ki Mayev, barantanın Türklerin bozkır hayatında anlaşılabilir bir 
yer tuttuğunu doğru okumakla birlikte uygulamanın keyfiyete bağlı olduğu fikrinde yanılgıya düşmüştür.

Hakkını iyilikle veya hâkim kararına rağmen alamayan kişi, düşmanının veya onun kabilesine mensup birinin malından almak suretiyle hasmını yargı karşısına çıkarmaya zorlardı. Barantanın şartlarının oluşabilmesi için muhataplardan birinin diğerini tahkir etmesi, şiddet kullanması, namusuna dokunması, öldürmesi veya törelere muhalif eylemlerde bulunması gerekirdi. Barantanın şartları sağlandığında haklı taraf hasmına yaşadıkları anlaşmazlık nedeniyle malına el koyacağını bildirir, muhatabın veya o yoksa yakınlarının mallarını (at, deve, koyun, sürüler vs.) alırdı (Donuk 1992, 64). Baranta temelde anlaşmazlığa ilişkin çözümler tükendiğinde, bireyin ve bağlı olunan boyun onurunu muhafaza etmek amaciyla ve misilleme yoluyla anlaşmazlıkları çözme metodu şeklinde de yorumlanabilir. Sık sık rastlandığı şekilde eğer borç ödenmeden kalır veya başlık parası tam zamanında teslim edilmezse baranta meşru bir yol olarak görülürdü. Bazen de taraflar toprak tartışmaları hususunda anlaşmazlığa düşerek baranta yoluna başvurulabilirdi. Ancak baranta hiçbir şekilde zenginlik elde etme yolu değildi. Bu realite halk arasında söylenen "Servetini baranta yoluyla artıramazsı" ifadesinde de kendini göstermektedir (Martin 2001, 251-252).

Kazakların sosyal hayatıyla ilgilenen ilk ciddi araştırmacı olan Alexei Levshin'in belirttiğine göre barantanın en önemli koşulu kanunen alacaklı olmak, barantayı boybeyinin izni ve bilgisi dâhilinde uygulamak ve kişinin alması gerektiği kadar malı alarak bu durumun tekrar boybeyine bildirilmesiydi. Bu koşullar karşılanmadığı takdirde söz konusu eylem suç kabul edilerek hırsızlık adı altında değerlendirilirdi. Boylar veya kişiler arasındaki anlaşmazlık öncelikle yargı makamına sunulurdu. Eğer suçlu kişi suçunu itiraf etmez ve oradan da müspet bir netice çıkmazsa yargının ve boybeyinin bilgisi dâhilinde barantaya başvurulurdu. Suçlu kişi eğer adalete itaat etmez, onların şefleri olayı incelemekten kaçınır ya da suçtan yana bir tavır alırsa bu durumda davacıya şefi tarafindan misilleme yapma hakk1 verilirdi. Fakat dönüşünde davacı bir açıklama yapmak zorundaydı (de Levchine 1840, 400). Tarafların davası bittiğinde ise barantanın miktarı hesaplanırdı. Gözden kaçan veya bilinmeyen mallar sırımta olarak adlandırılırdı. Kazaklar arasında bu durumu anlatan "bilse barımta, bilmese sırımta" şeklinde bir de atasözü bulunmaktadır (Tamir \& Arıcan 1997, 272). Yine Kırgızlarda da barantaya ilişkin birtakım atasözleri türemiştir. "Hırsız zengin olmaz" ve "A ğılını korurken komşunu hırsızdan saymazsın" vb. (Saliev 2015, 70).

Bazen barantaya baranta ile karşılık verilmekteydi. Bu şekilde icra edilen barantaların ilin ve dirliğin bozulmasına neden olabileceği endişesi doğduğunda her iki kabilenin ileri gelenleri derhal duruma müdahale ederek sulhu temin ederlerdi. Bu aşamadan sonra dâva Halk beylerinin hâkimlerinin fevkalâde kongresinde çözüme ulaştırılırdı (İnan 1998, 287). Burada dikkat edilen nokta toplumsal düzenin bozulmaması ve anlaşmazlıkların içtimai düzende kalıcı zarara sebebiyet vermemesi için önlemler almak gerektiğiydi.

Rus yazar Grodekov barantanın örf ve adetlere uygun olarak yapılması için belirli şartların olması gerektiğini vurgulamaktadır. Bunun için saldırının baranta olduğunun açıkça duyurulması, barantanın gündüz vakti yapılması, bir mağduriyetin giderilmesi ve zararların tazmini gayesiyle yapılması gibi hususların şart olduğunu ifade etmektedir (Donuk 1992, 64).

Barantanın neticeleri bahsinde bilhassa sosyal düzeni alakadar eden hususlar önem arz etmektedir. Zira Türk toplulukları arasında yaşanan baranta çekişmesinin yarattı̆̆ düşmanlık tüm önlemlere rağmen uzun bir süre devam edebilirdi. Çünkü zarara uğrayan tarafın şeref ve haysiyetini tekrar temin etmek adına karşı atağa geçmesi olağan dışı değildi. Bu durum içtimaî düzeni zaman zaman tehdit eden bir hal alabiliyordu. Baranta her durumda mükemmel işleyen bir sistem değildi. Zaman zaman boylar arası sert çatışmalara ve yaşanan ölümler neticesinde 
uzun süren kan davalarına da dönüşebilmekteydi. Bu sebeple yerini yurdunu terk etme durumda kalan boyların sayısı da az değildi. Orta Asya'dan çeşitli coğrafyalara, özellikle de Batı'ya yapılan göçlerde barantanın etkili bir âmil olduğu düşünülebilir. Türklerin bulundukları coğrafyaları terk etmelerinde daha ziyâde ekonomik gelişmelerin rolü vurgulansa da boylar arası mücadeleler ve baranta hadisesinin yarattığı içtimaî sonuçları da dikkate almak gerekir.

Baranta hadisesinin bir yönü de kuvvet üstünlüğünü temsil etmesidir. Barantaya katılanlar methiyeler ile taltif edilmekte ve batir (kahraman) ünvanı almaktaydılar. Barantaya katılmayanlar ise saygı görme hakkına sahip değillerdi (Vambery 1885, 306). Hem kişisel başarıyı hem de cemiyetin onurunu temsil eden baranta hadisesi, cesaretin ve dayanıklılığın ifadesi olarak görülürdü. Diğer bir deyişle adeta destansı bir mücadelenin manzumesini oluşturmaktaydı.

Ünlü âlim Barthold baranta uygulamasını, bozkırlarda düzenli hükümetin bulunmadığı ve hükümlerin uygulanmasının hâkimin (bi) şahsi nüfuzuna ve iki tarafın niyetine bağlı olduğu zamanlarda halkın çoğu zaman haklarını bizzat elde etmeye çalışması şeklinde yorumlamaktadır. Barthold'a $(1979,310)$ göre, bir şahsın işlediği suçun mesuliyeti tüm kabileye yüklendiğinden suçlu şahsın cezalandırılması yerine çok defa kabile cezalandırılırdı. Böyle bir barantanın yarattığı intikam hissi, yağma serbestisini doğurarak senelerce devam edebilirdi. Barthold'un ifadelerinde birtakım hatalı noktaların bulunduğu anlaşılmaktadır. Öncelikle herhangi bir şahsın işlediği suçun birinci dereceden sorumlusu kendisidir. Yarg1 var olan anlaşmazlığa binaen suçluyu muhakeme sürecinden geçirmekle yükümlüdür. Bu süreç davalının çözüme yanaşmaması sonucu tıkandığında baranta devreye girerdi. Bu noktada suçlu kimsenin avlusuna yapılacak baskın birinci derecede kendisinin mal ve mülkünü ele geçirmek amaciyla yapılırdı. Fakat suçlu kimsenin bulunmadığı durumlarda akrabalarının malları da ele geçirilebiliyordu. Elbette istisnaları görülmekle beraber bu hususunda da belirli bir kurallar bütününe tâbi olduğunu unutmamak gerekir.

Özellikle çeşitli Kazak toplulukları arasında toprak hâkimiyeti konusunda ciddi mücadeleler yaşanmakta ve bu durum da zaman zaman zayıf grupların azalmasına neden olmaktaydı. Söz konusu süreçte kaybeden kimseler baskın veya düşman komşuların tehlikesine rağmen çobanlığa veya tarıma yönelirlerdi (Pierce 1960, 156). Bu husus barantanın sosyal ve ekonomik yönü itibariyle de sonuçlarını anlamamızı sağlamaktadır. Bozkır yaşam koşullarının kendi içindeki sertlik, çoğu zaman güçlünün ayakta kalmasına güçsüzün ise bertaraf edilmesine neden olabiliyordu

\section{Bir Hukukî Müessese olarak Baranta}

Barantanın Bozkır Türk toplumlarında belirli bir yasal çerçevede değerlendirildiği açıktır. Bozkır nizamının bir parçası olan baranta, temelde bir haksızlığı ve gayri meşruluğu gidermeye yönelik atılan bir adımdır. Bu bakımdan bozkır hukukunda geçerli ve meşru bir uygulama olarak telakki edilmelidir. Ne yazık ki Batılı birçok araştırmacı barantanın salt sürü hırsızlığı ve yağma akını olduğunu ileri sürerek pek haksız değerlendirmelerde bulunmuştur. Halbuki Türk topluluklarında hırsızlık suçunun çok ağır yaptırımları olduğu devrin kaynaklarında zikredilmektedir. XIV. yüzyılın ünlü seyyahı İbn Battûta bu hususun altını bizzat çizmektedir:

"Türkler hayvan çalanın cezasını şöyle belirlemişler; hırsız ya çaldı̆̆ı hayvanın benzerinden dokuz adet getirecek yahut evlâtlarını teslim edecek davalıya! Eğer evlâdı da yoksa hırsızı koyun gibi boğazlıyorlar..." (İbn Battûta Tancî 2017, 374).

Seyyah İbn Battûta ile çağdaş olan el-Ömerî de eserinde barantaya ilişkin bir gözlemini dile getirmesine karşılık, uygulama bütününü doğru bir şekilde anlayamadığı gerçeği ifadelerinde kendini göstermektedir: 
“...Keza birisi bir başkasının malını çalarsa, malı çalınan kişi hırsızın mallarını ve çocuklarını çalıp satma hakkına sahiptir..." (El-Ömerî 2014, 120).

Görüldüğü üzere baranta geleneği çoğu zaman kural ve kaidesiz bir hareketin ifadesi olarak değerlendirilmiş, Türk içtimaî hayatının kendine mahsus dinamikleri yeterince anlaşılamadığı için abartı yorumlarda bulunulmuştur. Söz konusu örnekte el-Ömerî baranta hadisesini anlatırken pek yanlış şekilde köleliği ihtiva eder bir betimlemede bulunmuştur.

Kazak Hanı Tavke Han'ın (1680-1718) yasaları olan Yedi Yargı'da baranta hakkındaki kanun konumuz açısından önem arz etmektedir. Yedi Yargı'da Kazak geleneklerinde hırsızlık, soygun ve yağmanın ağır suçlar arasında değerlendirildiği, barantanın ise kanunda belirtildiği gibi yasal bir hak olduğu görülmektedir (Doğan 2002, 74). Bu durumu doğrulayan en önemli noktalardan biri baranta esnasında ölüm veya yaralanma yaşandığı durumlarda suç işlediğine kanaat getirilen kişilerin cezalandırılmalarıdır.

Baranta hadisesinde hâkimlerin kararları bağlayıcı bir nitelik taşımaktaydı. Eğer suçlu mahkeme kararlarını kabul etmez ve mahkemeye gelmeyi reddederse davacılar zararlarını tazmin etmek için suçlu kimselerin mallarına karşı baranta başlatabilirdi. Boy liderleri ve hâkimler davacının iddia ettiği yasal alacaktan daha fazla mal elde etmediğinden emin olmak zorundalardı. Bu sayede kabile liderleri ve ileri gelenler olası düşmanlıkları kontrol altına alabiliyorlardı. Bununla birlikte bazen dengelerin sağlanamadığını, büyük grupların zayıf rakiplerine karşı üstünlük kurabildiklerini de belirtmemiz gerekiyor (Geiss 2003, 34, 118).

Görüldüğ̈̈ üzere devrin kaynaklarında barantaya ilişkin birtakım bilgiler bulunmaktadır. Yalnız burada dikkat edilmesi gereken nokta barantanın keyfi bir biçimde uygulanmadığı ve belirli kurallara sahip olduğu gerçeğidir. Söz konusu husus barantaya meşru ve hukukî bir zemin oluşturmaktadır. Zira anlaşmazlık durumunda ilk olarak başvurulacak merci yargıdır. Zarara uğrayan kişi sadece çalınan malı değerlinde baranta alır ve boybeylerine eyleme ilişkin gerekli izahat verilirdi. Aksi halde haklı olan kişi kurallara uymadığı gerekçesiyle cezaya çarptırılırdı. Bununla birlikte baranta olarak alınan hayvanlar hamile ise doğum sonrasında yavruları baranta yapılan kişiye iade edilmektedir. Aksi halde kişiye hırsızlık yaptığı gerekçesiyle icap eden muamelede bulunulurdu. Bu hususlara rağmen birçok batılı araştırmacı baranta hadisesini, çiftlik hayvanlarını ele geçirmek için yapılan kanlı akınlar, zalimlik, hukuksuzluk, güçlünün zayıfı ezmesi ve hatta anarşi olarak görmekten kaçınmamışlardır. V. von Gern baranta hadisesini sadece bir haksızlık olmasının ötesinde Kazak yaşam biçiminin büyük bir eksiği olarak görmüş ve olumsuz betimlemelerde bulunmuştur (Campbell 2011, 43, 259). Fakat görüldüğü üzere baranta gelişigüzel bir uygulama olmayıp sıkı kurallar manzumesine uygun şekilde icra edilen bir gelenekti.

\section{Modern Zamanlarda Baranta}

Yerleşik kültürlerin bozkır topluluklarındaki geleneklere karşı bakış açısı çoğu zaman sathi olmuştur. Çünkü yerleşik toplulukların kültürleriyle Asya konargöçerlerinin töreleri birbirinden farklıdır. Türklerdeki baranta geleneği ve buna benzer geleneksel normlar yerleşik kültür temsilcileri tarafından çoğu zaman kınanmıştır. Oysaki bu hadiseler Türkler ve diğer bozkır kavimleri açısından günlük yaşam pratiğinin bir parçası olarak kabul edilmiştir (Bogdanov 2009, 474).

Ekonomik koşulların ve sosyal hayattaki esasların değişmesiyle geleneksel hukukta yer alan birçok diğer kurum gibi baranta da eski önemini kaybetti. Terim esas anlamını zaman içerisinde yitirerek basit bir hırsızlık mânâsında telakki edilmeye başlandı. Fakat kadim geleneklerin hâkim olduğu belirli sahalarda geçerliliğini sürdürdü (Arat 1986, 1037). XIX. yüzyılın ilk 
yarısında Rusya'nın bozkırlar üzerindeki genişleyen kontrolü kabileler arasındaki mücadeleleri ve baranta hadisesinin seyrini de değiştirdi. Rus devletinin hukuk sistemi içinde durdurulması gereken bir suç olarak telakki edilmeye başlandı ve Rusların ceza yasalarında yerini buldu (Kachkeev 2007, 105).

Baranta, 1822 yılında Sibirya'da yaşayan Kazak beyleri tarafindan örf ve adetler kapsamından çıkartılarak bir suç olarak değerlendirilmiştir. 1868 'de sahra vilayetlerinin idaresine ilişkin düzenlemeyle baranta hadiselerinin devlet mahkemeleri tarafindan çözüme ulaştırılması kararlaştırılmıştır. 1920'de Sovyet hükümeti çıkardığı bir kararnameyle bundan böyle barantayı yasak eden ve baranta hadisesine karışanların suçlu kabul edileceğine dair bir kararname daha neşretmiştir. Merkez icra komitesinin 16.10.1924 tarihli kararıyla baranta, yağma, çapul ve hırsızlıktan ayrı değerlendirilmiştir. Bu suretle baranta, gelenekler kapsamında mütalaa edilerek namus ve şerefi korumaya yönelik meşru bir davranış olarak kabul görmüştür (Donuk 1992, 65).

Rus literatüründe baranta ve çapul sözcüğü sıklıkla yer değiştirmiştir. 1886'da Sibirskaia gazetesindeki bir makalede baranta terimi, Kazaklar tarafından tekrarlanan at hırsızlı̆g hadiseleri olarak tanımlanmıştır. Bozkır askeri valisinin 1898'deki yıllık raporunda da baranta sığır hırsızlığı olarak ele alınmıştır. Diğer taraftan Kazak Türklerinin ünlü bilgini Çokan Velihanoğlu barantaya yönelik Rus önyargılarını ifade ederken aslında bunun bir cinayet olmadığını fakat kelimenin duyuluşundan meşum olduğunu vurgulamıştır (Martin 2001, 257-258).

Sadece Bozkır Türk toplumları değil zaman zaman Ruslar da baranta hadisesine tanık olabiliyordu. 1701'de Rus süvari İvan Balaban Azov'da farkında olmadan bir fidye olayının mağduru oldu. Yine Temirkazi isimli bir Tatar, Don Kazakları tarafindan esir alındı (Boeck 2009, 51). Ruslar aslında mahalli kurumları yasal çerçeve kapsamında kontrol altına almaya çalışmış fakat barantaya karşı ciddi bir mukavemet de göstermişlerdir (Rusların Barantaya yönelik bakış açıları ve kanun düzenlemeleri için bk. Saliev 2015, 69-74).

\section{Sonuç}

Temelde çiğnenmiş olan adalete işlerlik kazandırmanın bir aracı olan baranta geleneğini askeri akınlardan ayırmak gerekmektedir. Çünkü barantayı icra edenler kan davasına veya daha büyük düşmanlıklara sebebiyet vermemek için dikkat göstermek mecburiyetindeydi. Kadim bozkır hukukunun bir parçası olan baranta, belirli kurallar manzumesi halinde icra edilirdi. Baranta hadisesinin meşruiyet çerçevesini oluşturan üç önemli aşama bu hususu daha da açıklar niteliktedir. Yaşanan anlaşmazlığın veya haksızlığın tespiti ile başlayan bu süreç, davacının anlaşmazlığı yargıya taşımasıyla devam eder ve davalının yargı önüne çıkarılması için yapılan çabalar ile son bulur. Eğer bu üçlü aşamadan sonra sorun halen çözülememişse boybeyi ve yargının bilgisi ve izni dâhilinde, izin verilen kurallar dairesinde ve sadece zararın tazmini maksadıyla baranta icra edilirdi. Hadise sonrasında ise barantanın miktarı hesaplanırdı. Diğer taraftan halk arasında söylenegelen söz ve deyimlerde barantanın zenginlik vasıtası olmadığı da açıkça belirtilmiştir. Görüldüğü üzere baranta birçok amilin bir araya gelmesi koşuluyla icra edilir ve çeşitli kontrol mekanizmalarıla denetlenirdi.

Baranta geleneği maalesef bugüne kadar Türk araştırmacıları yeterince meşgul etmemiştir. Bununla birlikte batılı birçok yazar barantayı bir kan davası veya basit birer hırsızlık uygulamasından farksız görmemiştir. Batılı araştırmacıların iddia ettiklerinin aksine baranta, keyfiyete bağlı bir yağma hareketi olmayıp belirli kural ve kaideler bütünü içerisinde icra edilen bir uygulamadır. Yapılan yüzeysel değerlendirmelerde konunun inceliklerine nüfuz edilmediği apaçık ortadadır. Konuya ilişkin bütüncül ve eleştirel bir değerlendirmede bulunduğumuzda, derin tarihi köklere sahip olan bu geleneğin kendi çağının bağlamında değerlendirilmesinin zorunlu olduğunu ifade etmek gerekmektedir. 
Kendi içerisinde bir bütünlüğe sahip bozkır hayatı tetkik edilirken topluluğu yaşatan kültür öğeleri çoğu zaman ihmal edilmektedir. Baranta geleneğine ilişkin yapılan değerlendirmeleri de bu hususlardan bağımsız ele almak mümkün görünmemektedir. Genel bir ifadeyle söylenecek olursa, Eski Türk içtimaî hayatı maalesef göçebelik nazariyesine paralel yorumlardan istisna tutulamamaktadir.

\section{KAYNAKÇA}

Arat R. R. (1986). "Baranta". The Encyclopaedia of Islam. Vol. I (1986). Leiden.

Barthold W. (1979). "Baranta". İslâm Ansiklopedisi. Cilt 2 (1979). İstanbul.

Boeck B. J. (2009). Imperial Boundaries: Cossack Communities and Empire-Building in the Age of Peter the Great. New York 2009.

Campbell I. W. (2011). Knowledge and Power on the Kazakh Steppe, 1845-1917. Basılmamış Doktora Tezi. Michigan Üniversitesi. Michigan 2011.

Chibilev A. A. \& Bogdanov S. V. (2009). "The Legacy of Nomadic Empires in Steppe Landscapes of Northern Eurasia". Herald of the Russian Academy of Sciences 79/5 (2009) 473-479.

de Levchine A. (1840). Description des Hordes et des Steppes des Kirghiz-Kazaks ou Kirghiz-Kaissaks. Paris 1840.

Diyarbekirli N. (1972). Hun Sanatt. İstanbul 1972.

Doğan O. (2002). "Tavke Han Dönemi (1680-1718) Kazak Hanlığı ve Tavke Han Yasaları (Jetı Jargı)". Manas Üniversitesi Sosyal Bilimler Dergisi (2002) 60-81.

Donuk A. (1992). "Baranta". TDVIA. Cilt 5 (1992). İstanbul.

Ebû Abdullah Muhammed İbn Battûta Tancî. (2017). İbn Battûta Seyahatnâmesi. Çev. A. Sait Aykut. İstanbul 2017.

Geiss P. G. (2003). Pre-tsarist and Tsarist Central Asia: Communal Commitment and Political Order in Change. New York 2003.

Gökalp Z. (1991). Türk Uygarlı̆̆g Tarihi. İstanbul 1991.

Kassymova D., Kundakbayeva Z. \& Markus U. (Haz.) (2012). Historical Dictionary of Kazakhstan. Toronto 2012.

İnan A. (1998). “Kazak-Kırgızlar'da Yeğenlik Hakkı ve Konuk Aşı Meseleleri”. Makaleler ve İncelemeler I (1998). Ankara.

Kachkeev M. (2007). Stellung der Richter in Kirgistan und Kasachstan: Eine Analyse vor dem Hintergrund der allgemein anerkannten rechtsstaatlichen Prinzipien und der historischen Entwicklung der Justiz in diesen Ländern. Berlin 2007.

Kafesoğlu İ. (2017). Türk Milli Kültürü. İstanbul 2017.

Krader L. (1955). "Principles and Structures in the Organization of the Asiatic Steppe-Pastoralists". Southwestern Journal of Anthropology 11/2 (1955) 67-92.

Kurat A. N. (1972). IV-XVIII. Yüzyllarda Karadeniz Kuzeyindeki Türk Kavimleri ve Devletleri. Ankara 1972.

Martin V. (2001). "Barymta: Nomadic Custom, Imperial Crime". Eds. Daniel R. Brower, Edward J. Lazzerini. Russia's Orient: Imperial Borderlands and Peoples 1700-1917. (2001) 249-270. Indianapolis.

Lessing F. D. (Ed.) (1960). Mongolian-English Dictionary (1960). Los Angeles 1960.

Pierce R. A. (1960). Russian Central Asia, 1867-1917: A Study In Colonial Rule. Los Angeles 1960.

Prior D. (2013). The Šabdan Baattr Codex: Epic and the Writing of Northern Kirghiz History. Boston 2013.

Radloff W. (1956). Sibirya'dan I. Çev. A. Temir. İstanbul 1956.

Radloff W. (1893). Versuch eines Wörterbuches der Türk-Dialekte (Opit Slovarya Tyurkskih Nareçiy). St. Petersburg 1893.

Ramstedt G. J. (1952). "Marginal Notes on Pashto Etymology”. Studia Orientalia XVII-V. Helsinki 1952.

Räsänen M. (1969). Versuch eines Etymologischen Wörterbuchs der Türksprachen. Helsinki 1969.

Saliev A. L. (2015). Ob İnstitute "Barımtı" v Obıçnom Prave (adate) Koçevnikov tsentralnoy Azii (Po Arhivnım i Pravovım Materialam). Vestnik KRSU 15/2 (2015) 69-74.

Şeyh Süleyman Efendi-i Buharî. (1298/1881). Lugat-i Çağatayî ve Türkî-i Osmanî, Cild-i Evvel. İstanbul $1298 / 1881$. 
Şihabeddin b. Fazlullah El-Ömerî. (2014). Türkler Hakkinda Gördüklerim ve Duyduklarım (Mesâliku'lEbsâr). (Çev. Ahsen Batur). İstanbul 2014.

Tamir F. \& Arıcan H. (1997). Muhtar Ävezov, Seçilmiş Hikâyeler. Ankara 1997.

Vambery H. (1885). Das Türkenvolk in seinen Ethnologischen und Ethnographischen Beziehungen. Leipzig 1885.

Vasmer M. (1953). Russisches Etymologisches Wörterbuch. Erster Band. Heidelberg 1953.

Yudahin K. K. (1998). Kırgız Sözlüğ̈̈. Cilt I. Çev. A. Taymas. Ankara 199. 